\title{
Erratum to: Solvent effect on the complex formation of polyvinylpyrrolidone and polymonomethy itaconate
}

\author{
M. Anasagasti • R. Valenciano • Issa Katime • I. Rivas
}

Published online: 1 March 2013

(C) Springer-Verlag Berlin Heidelberg 2013

\section{Erratum to: Polym Bull (1992) 28:669-676 DOI 10.1007/BF00295971}

In the original article, one of the author name was not correct. L. Bivas should read I. Rivas.

The online version of the original article can be found under doi:10.1007/BF00295971.

R. Valenciano $\cdot$ I. Katime

Departamento de Química-Física (Physical-Chemistry Department), Facultad de Ciencias y Tecnología, Universidad del País Vasco EHU (Basque Country University), Bizkaia, Spain e-mail: rb.valenciano@ehu.es

I. Katime

e-mail: Issa.katime@ehu.es

I. Rivas $(\bowtie)$

Departamento de Salud Ambiental, (Environmental Health Department), IEFPS Tartanga, Educational Department of the Basque Country, 48950 Erandio, Bizkaia, Spain e-mail: irivas@irakasle.net 